\title{
Reliability of Turbine Blades in Wet Steam Conditions
}

\author{
Galina Ilieva \\ C-MAST, University of Beira Interior, 6201-001 Covilhã, Portugal
}

\begin{abstract}
Blades of steam turbine are the most important element of energetic systems. Blades failure leads to various exploitation problems, efficiency decrease and economical losses, at all. The present research deals with study on erosion mechanisms in a low pressure stage of an industrial steam turbine. Aerodynamic behavior and efficiency of energy conversion, trajectories of water particles, reasons for occurrence of erosion wear and erosion of certain parts of the streamlined surfaces, are established and discussed. An approach to obtain incidence time to erosion appearance is implemented. Developed methodology and obtained results are applicable to determine erosion effects on streamed complex surfaces, to consider approaches to lower wetness in condensation turbines and prolong the reliability of blades operated in wet steam conditions.
\end{abstract}

Keywords: Droplet diameter; Incidence time; Water droplet erosion; Water droplets trajectories; Water hammer pressure

\section{Introduction}

Erosion of turbine blades leads to rough surfaces, changes steam flow paths and decreases efficiency. Water droplets after condensation deposit mainly on the trailing edges of the stator blades and then are swept off the trailing edges by the incoming expanding steam flow. Relatively large and characterized with low velocity water droplets hit the leading edge of rotor blades, leading to cracks on the surfaces and loss of blade material $[1,2,3,4]$.

Both the erosion and deposition phenomenon change surface finish and shape of leading and trailing edges, increases surface roughness, etc. That is why a strong knowledge and fundamental understanding of erosion parameters is essential to prolong the life of blades operated at wet steam conditions. Many research works have been conducted to study in details the erosion mechanisms and their impact on blades surfaces. Condensation and its specific features in steam turbines were intensively studied by A. Stodola and described in [5]. In next decades, research on that phenomenon in steam turbines and ways to increase their efficiency and reach long-lasting exploitation, received considerable attention in $[6,7,8,9,10]$ A detailed survey of condensation in flows with high speeds is presented in [11].

A relationship between roughness change and size of radial clearance in function of the erosion is presented in [38].

Parameters such density, wet steam quality, impact velocity, size of droplets, ultimate tensile strength, hardness of the material, pressure, temperature and viscosity, play a significant role in the process of erosion over turbine blades, [12] and must be intensively studied.

In $[13,14]$ are provided insights on the increased rate of erosion on both leading and trailing edges of stator blades and proved that the erosion is a reason for roughness to appear.
In $[15,16,17,20]$ is found that degree of erosion is a function of the angle at which the fluid particles enter in the interblade passage, their speed and size.

In [18] obtained results indicate that erosion damage over blades depends mainly on the first impingement of every solid particle on the wall, after entering into the cascades, and the erosion rate of the first impingement is much larger than the one caused by additional impingements on the wall after particle rebounding.

It is empirically found that water droplet erosion rate is proportional to approximately the fifth power of the impact velocity if all other parameters remain constant, [19]. The erosion increases with increase of blade length and peripheral rotational velocity.

Research on water droplets "impact over leading edge surface is discussed in [20]. Water film, formed over the stator blades, flows in a direction to the trailing edge, influenced by force, produced due to the steam drag, the impulse of the fog deposition and the pressure drop realized along the turbine blade as shown in $[21,22]$.

When liquid impacts on surface, it behaves as a compressible fluid, in the early stage, and the so called, ,water hammereee pressure can be generated. This high pressure is responsible for most of damages resulting from liquid impacts, and the high pressure is maintained while the edge of the contact area, between the impacting liquid and the solid, moves supersonically with respect to the shock speed in the liquid, [23].

Contemporary research works are focused on condensation modeling [24], numerical modeling and analysis of erosion parameters and their impact on blade surfaces, [15, 26, 27, 32]. Based on erosion rates and particle models, all the erosion characteristics of first row blades in a supercritical steam turbine, was simulated and analyzed by threedimension numerical simulation method, [28]. 


\section{International Journal of Science and Research (IJSR) \\ ISSN (Online): 2319-7064}

Index Copernicus Value (2013): 6.14 | Impact Factor (2014): 5.611

On the basis of the fulfilled literature survey, one can conclude that not many papers are involved in numerical simulations (to obtain main problematic zones on the blade surfaces) and approaches to calculate main characteristics, in a close relation with the occurrence and rate of erosion.

The aim of this study is to model, simulate, analyze and evaluate the impact of erosion on blade performance and to introduce a model to calculate the incidence time to erosion to appear. This research is crucial to determine the impact of the secondary phase on the aerodynamic behavior and efficiency of energy conversion.

\section{Problem set up}

\subsection{Geometry formulation}

The turbine stage, object of current research, is in exploitation in double-flow, low pressure turbine. Geometry is built and meshed in Gambit after a number of specific approaches to overcome mesh problems and attain high quality grid were applied [39].

For mesh purposes, Cooper's discretization scheme was applied. This scheme follows the blade shape changes in radial direction, in the process of volume grid generation. This is very important option, which helps negative volume elements and elements with bad quality such as high skewness to be avoided. Boundary layer is highly resolved in a close proximity to the streaming walls, the idea is to obtain correct results for particles ${ }^{\text {ec }}$ impact over the blade surfaces

\subsection{Numerical Formulation}

Numerical simulations were accomplished in Fluent, with implemented user defined code. This code includes equations to model distribution of particles through the stage, interaction among them and forces impact over the blade surfaces.

Fluid is wet steam - turbulent, compressible and viscous. Fluid physical properties are as follows: density is varying with the ideal gas law; viscosity is $0.0000134 \mathrm{~kg} / \mathrm{m} . \mathrm{s}$; thermal conductivity is $0.02161 \mathrm{~W} / \mathrm{m} . \mathrm{K}$.

Boundary zones are "pressure inlet", "pressure outlet", "periodic", "wall" and "fluid". The total gauge pressure, static pressure, static temperature, turbulence parameters and flow direction were imposed as "pressure inlet" boundary conditions. Static pressure, static temperature, flow direction and turbulence parameters were implied as outflow boundary conditions. Periodic boundary conditions were imposed along the aside zones. No-slip conditions to blade surfaces were applied.

Moving rotor blades and the interaction effects between stator and rotor are modeled by "mixing plane" model - flow parameters are spatially averaged at the mixing plane interface zone.
In this research, Realizable $\mathrm{k}-\varepsilon$ closure model is applied. Modelling with Realizable $\mathrm{k}-\varepsilon$ turbulence model is appropriate because the model includes effects of mean rotation in the turbulent viscosity term, as discussed in [29]. This model predicts boundary layer growth along the trailing edge, from the suction side of the blade, as shown in [30].

\subsection{Mathematical model and specific parameters included in the numerical procedure}

Discrete two-phase model for prediction of discrete phase trajectories, by integration the force acting on particles, written in Lagrangian reference frame, is applied [31]. This force balance equates the particle inertia and is presented by eq.(1) in Cartesian coordinates:

$d \mathrm{u}_{p} / d t=F d\left(u-u_{p}\right)+g_{i}\left(\rho_{p}-\rho\right) / \rho_{p}+F i$

"i" denotes $\mathrm{x}, \mathrm{y}, \mathrm{z}$ axis of the coordinate system.

Drag force $F_{D}$ can be calculated after application of eq.(2)

$$
F d=18 . \mu \cdot C d \cdot R e /\left(24 . \rho p \cdot d p^{2}\right)
$$

Drag coefficient Cd can be taken from eq.(3)

$$
C d=a_{1}+a_{2} / R e+a_{3} / R e^{2}
$$

In eq.(1), $F d(u-u p)$ gives drag force per unit particle mass. In " $\mathrm{Fi}$ " term are also included forces that arise due to the rotation of the reference frame.

Initial inputs for discrete phase calculations are velocity, trajectory and temperature of water droplets; mass flow rate; model of interaction between saturated steam and water particles, etc. These parameters provide starting values to calculation of dependent discrete phase variables that describe the instantaneous states of every particle. The "pressure-inlet" zone is defined as a place from where particles are being injected into the flow. The discrete phase is uniformly distributed in the flow domain.

The erosion rate is defined in eq. (4) as a product of the mass flux and specified functions for the particle diameter, impact angle, and velocity exponent as is in eq.(4):

$$
\left.R_{\text {erosion }}=\sum_{p=1} \text { Nparticles }_{\text {m. }} \cdot C(d p) \cdot f(\alpha) \cdot v /\left(A_{\text {face }}\right)\right]
$$

In equations above: Aface area of cell face at the wall; $C(d p)$ function of particle diameter; $F i$-force due to acceleration in $\mathrm{x}, \mathrm{y}, \mathrm{z}$ direction; $R e$-Reynolds number; $u$ - flow velocity in $\mathrm{m} / \mathrm{s}$; up- particle velocity $\mathrm{m} / \mathrm{s} ; \alpha$-impact angle of the particle with the wall face; $f(\alpha)$-function of the impact angle; $\mu$ molecular viscosity in $\mathrm{kg} / \mathrm{m}^{3} ; \rho$-flow density in $\mathrm{kg} / \mathrm{m}^{3} ; v$ relative particle velocity; $b(v) \quad$ function of relative particle. Water particles were set up of type "inert". An "inert" particle is a discrete phase particle that obeys eq. (1) and is subject to heating or cooling via the thermodynamic law. Droplets are with spherical shape and their diameter distribution is of type "uniform". Droplets deformation, growth and rupture are not considered. Deposition is encountered when droplets fall on blade surfaces. Numerical 


\section{International Journal of Science and Research (IJSR) \\ ISSN (Online): 2319-7064}

Index Copernicus Value (2013): 6.14 | Impact Factor (2014): 5.611

simulations were accomplished for water droplets with diameter of 1, 5, 15 and 25 microns, having temperature 320 $K$. Particles velocity is variable and is in terms of their size and mass. The total mass flow of the secondary phase is $0.133 \mathrm{~kg} / \mathrm{s}$ (4.4\% wetness), responding to the real wetness measured in the turbine stage.

The Navier-Stokes equations set is solved with density based solver, fully implicit approach. Second order scheme for equations discretization is applied. Under-relaxation factors are set-up initially to 0.5 . Convergence factors are $10^{-4}$ for all unknown parameters, exception is energy equation with relaxation factor set to $10^{-6}$.

\section{Results}

Only some results of obtained erosion rates are shown here, fig. 1(a, b) and fig. 2(a, b). The primary water droplets, with diameter of 1 to 5 microns, that have small mass and velocities comparative with those of the steam particles, are following the main flow from one to another turbine stage. Only a small amount of those water droplets deposit on the stator and rotor leading edge surfaces and on the trailing edges of the rotor blades, fig. 1(a, b) - fig.2(a,b).

Water droplets with diameter from 15 to 25 microns are characterized with higher rate of deposition on blade surfaces and lead to increased erosion effects, fig. 2(a-d). Those droplets have larger mass and velocities less than steam particles and deposit mainly over the pressure side of the stator blades and over pressure sides of rotor blades, in a close proximity to the trailing edges. Also, water droplets are collected mainly along the leading edge from the suction side of the rotor blades, and along the trailing edge from the pressure side. The amount of collected droplets on the convex surface is higher than the one on the concave surface. Most droplets deposit after the turning point on the concave surface.

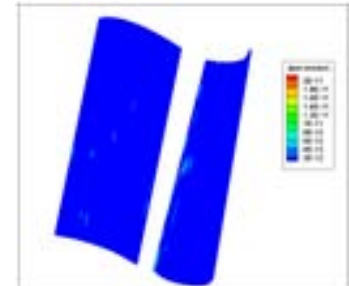

(a)

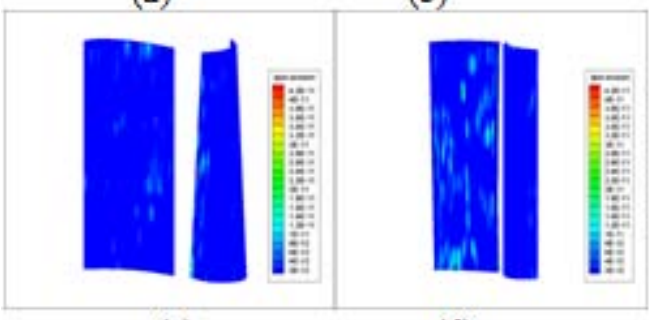

(c)

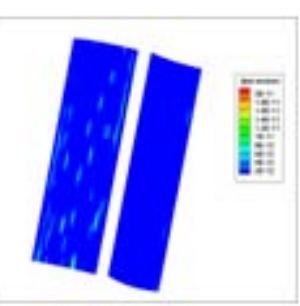

(b)

(d)
Figure 1(a, b, c, d): Erosion on blades surfaces - water particles with diameter 1 micron and wet phase mass flow rate $0.133 \mathrm{~kg} / \mathrm{s}$ - concave surface of stator blade and leading edge of the rotor blade (a), leading edge of the stator blade surface and concave surface of the rotor blade (b); for water particles with 1 micron diameter and wet phase mass flow rate $0.266 \mathrm{~kg} / \mathrm{s}$ - concave surface of stator blade and leading edge of the rotor blade (c), leading edge of the stator blade surface and concave surface of the rotor blade (d) .

Scaled velocity triangles, showing steam and water particles ${ }^{\text {ee }}$ velocity vectors, are presented in fig. 3 - fig. 6 . By the velocity triangles it is easy to verify that the larger the peripheral velocity $U$ and the angle of incidence, the bigger (at other equal conditions) the normal component of droplets velocity $W d r$, i.e. the impact force acting on a droplet increases.

For water particles with diameter 15 microns to 25 microns, absolute velocity $C 1 d r$ is less, their relative velocity $W 1 d r$ and its normal component are bigger than those of smaller water droplets, fig. 5 and fig. 6. Consequently, the impact force over a separate droplet, with increase of its diameter and mass, will grow faster than the droplet's mass. The quantity of $W 1 d r$ is a function of, as follows: rotor peripheral velocity $U$, flow angle at which droplets enter into the rotor channels, absolute velocity of vapor (the continuous phase), its density and magnitude of clearance between stator and rotor blades. In fig. 4 and fig. 6 are shown changes in velocity triangles in function of varying droplet diameters and their velocities at hub section. Relative component of velocity $W d r$ changes and water particles enter into the interblade rotor channels at increased impact angle. Last mentioned, together with the ratio of twistness (at hub active profile, at tip - reactive profile), lead to increase in the erosion patterns.

Changes in twistness, from one to another blade section, and droplets diameter lead to increase in the erosion levels on suction sides of rotor blades, in direction from hub to shroud. In fig. 3 and fig. 5 are shown changes in velocity triangles in function of varying droplet diameters and their velocities at the shroud section. The absolute velocity of water droplets is changing, water particles are entering into the inter-blade channels of stator, at increasing impact angle. This provokes increased erosion effects at the leading edge of stator blades. Increase in axial component of vapor speed, its density, magnitude of axial clearance between stator and rotor blades, leads to strong acceleration of water particles when passing through the axial clearance i.e., absolute velocity $C d r$ is increased and the impact force of droplet, against blade surface, decreases together with decrease in the normal component of water droplet speed. It is clear that with increase of ratio (U/C1normal) conditions for appearance of erosion become more favorable.

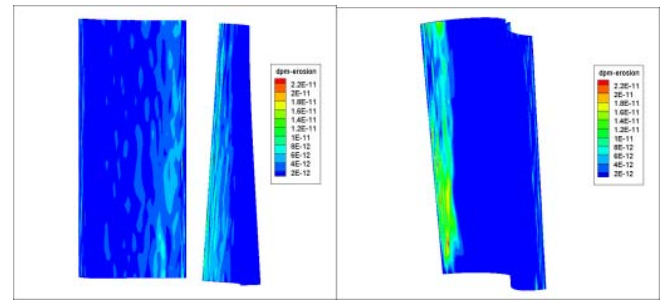

(a)

(b)

\section{Volume 5 Issue 3, March 2016}




\section{International Journal of Science and Research (IJSR) \\ ISSN (Online): 2319-7064}

Index Copernicus Value (2013): 6.14 | Impact Factor (2014): 5.611

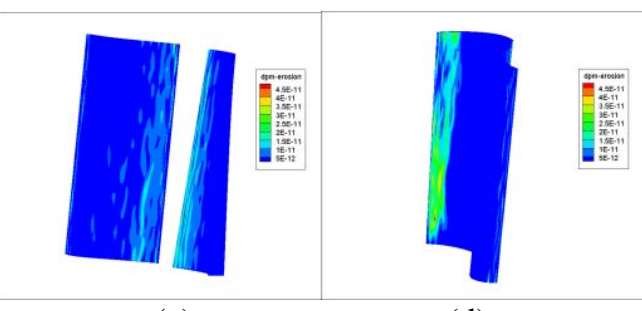

(c)

(d)

Figure 2 (a,b,c,d): Erosion on blades surfaces in case of water particles with $\mathrm{d}=1$ micron and wet phase mass flow rate $0.133 \mathrm{~kg} / \mathrm{s}$ - concave surface of stator blade and leading edge of the rotor blade (a), leading edge of the stator blade surface and concave surface of the rotor blade (b); in case of water particles with 25 micron diameter and wet phase mass flow rate $0.266 \mathrm{~kg} / \mathrm{s}$ - concave surface of stator blade and leading edge of the rotor blade (c), leading edge of the stator blade surface and concave surface of the rotor blade (d) .

Mainly, water droplets deviate due to their less velocities and larger mass, tend to impact on the blade and induce water droplets erosion in the area of leading edges, trailing edges and sidewalls of pressure and suction surfaces. In current study is found that other reasons to path digression are: changes in the shape of rotor blade sections from hub to tip; secondary vortices, formed along the pressure sides, which deviate streamlines; centrifugal forces that deviate particles to the tip sections; pressure differences in radial direction and secondary flows; change in axial gap size in radial direction. Results of detailed study show that water droplets erosion and damages are strongly related to the radius of curvature of the droplet at the point of impact. Therefore, distorted droplets, having radii larger than their initial diameters, are more erosive.

Efficiency decreases with increase of wet portion in twophase flow. In fig. 8 change in efficiency value for wet phase of $0 \%, 4.478 \%$ and $8.956 \%$ is demonstrated. It is proven that efficiency decrease is in a direct relation to the wet phase quality in the flow. In this study efficiency changes from $67.15 \%$ to $59.69 \%$, depending on the wet phase quantity.

Simulations show that in reactive stages the angle of this change will be less than in active, considering the change of direction relative to velocity of drops upon change of peripheral velocity. Consequently, impact of droplets in reactive stages will be distributed over a smaller area than in active stages, i.e. the negative influence of water droplets per $1 \mathrm{~cm}^{2}$ on the blade surface, in reactive stages will be higher than in active stages.

In Fig. 7 verification of the obtained results, is shown.

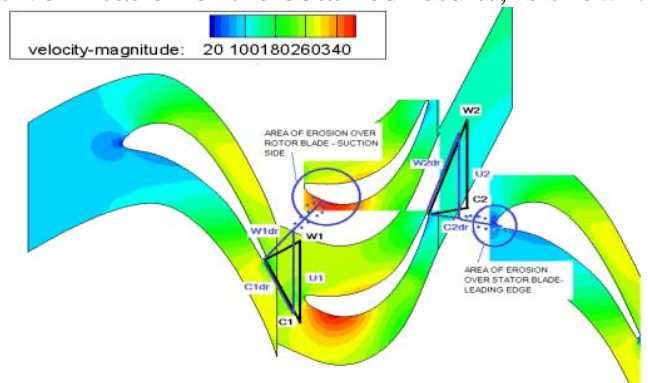

Figure 3: Velocity triangles of steam flow and water particles with diameter 1 micron - tip section.
In the research of Zhou et al (2008) is stated that when a spherical droplet impacts on a solid plane, a shock wave forms inside the water droplet. The water droplet thus imposes pressure, distributed (water hammer pressure) on the surface of solid, which varies with time and space, inducing stress waves. These waves are transmitting through the solid, with possible formation and propagation of micro cracks. The shock waves and the imposed pressure are dependent on the particles velocities, flow parameters, water droplets diameter and their mass.

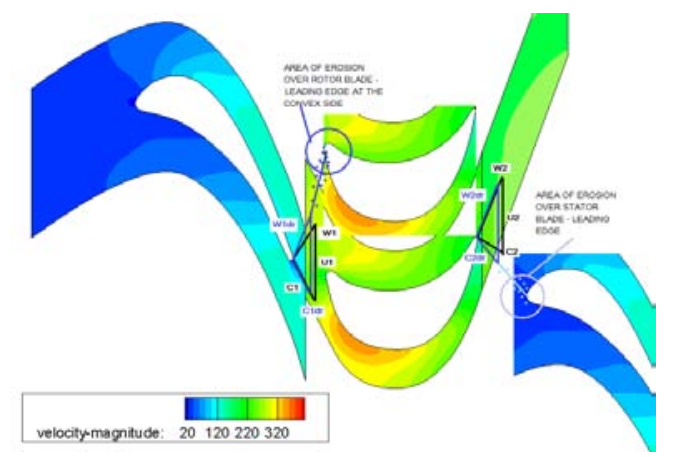

Figure 4: Velocity triangles of steam flow and water particles with diameter 1 micron - hub section.

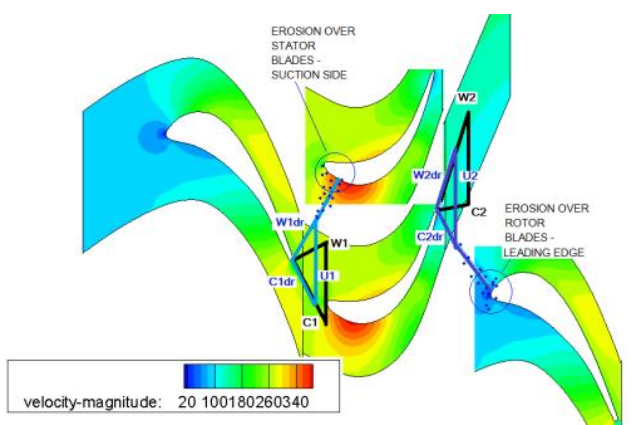

Figure 5: Velocity triangles of steam flow and water particles with diameter 25 micron - tip section.

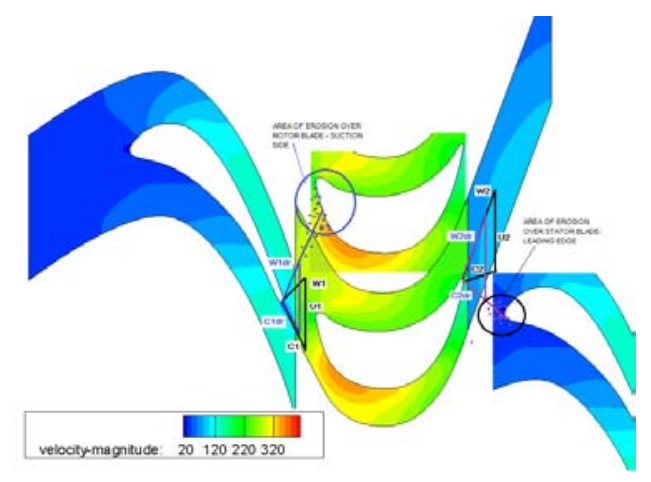

Figure 6: Velocity triangles of steam flow and water particles with diameter 25 micron - hub section. 


\section{International Journal of Science and Research (IJSR) \\ ISSN (Online): 2319-7064 \\ Index Copernicus Value (2013): 6.14 | Impact Factor (2014): 5.611}

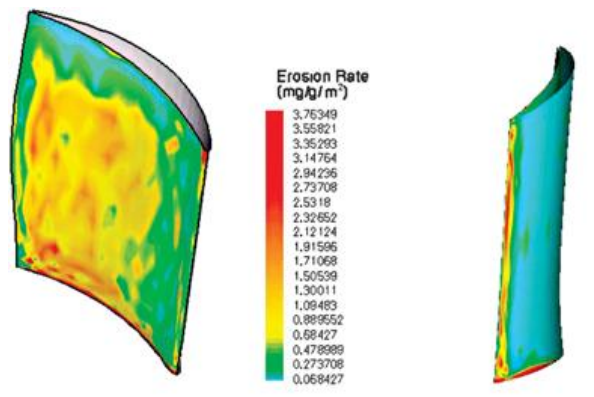

Figure7: Erosion over turbine blades after Hamed et al. [32].

Once numerical results are fulfilled, computations on erosion resistance of materials or what kind of covers could be applied against erosion wear could be performed.

In the aforementioned equations: $E_{S}$ - strength for the uncoated blade material; dp - particles diameter in m; $\Theta$ mean impact angle of water particles over blade surfaces; $\sigma e$ material's equivalent stress $\mathrm{MPa} ; \rho_{L}$ - density of water particles in $\mathrm{kg} / \mathrm{m}^{3}$; U-peripheral velocity in $\mathrm{m} / \mathrm{s}$; $\mathrm{m}$ - mass of wet phase in $\mathrm{kg} ; \rho p$ - particle density, $\mathrm{kg} / \mathrm{m}^{3} ; \rho_{S^{-}}$density of solid particles, $\mathrm{kg} / \mathrm{m}^{3} ; C_{L}$-sound speed in water, $\mathrm{m} / \mathrm{s} ; C_{S^{-}}$ sound speed in blade material, $\mathrm{m} / \mathrm{s} ; D$-diameter at hub, mid or tip section, $\mathrm{m}$.

In this study as impact velocity is accepted the one at which the section under consideration hits with water particles. It was clarified before that water steam droplets, depending on their size and mass, are travelling at speed equal or less of the steam flow speed. Results are described in Table 1.

Water hammer pressure effect increases in radial direction because sections from hub to tip meet water particles with gradually increasing peripheral velocity.

Table1: Results for three control sections

\begin{tabular}{|l|c|c|c|c|l|}
\hline $\begin{array}{c}\text { Param } \\
\text { eter }\end{array}$ & $\begin{array}{c}\mathrm{D} \\
{[\mathrm{m}]}\end{array}$ & $\begin{array}{c}\mathrm{U} \\
{[\mathrm{m} / \mathrm{s}]}\end{array}$ & $\begin{array}{c}\theta \\
{[\mathrm{deg}} \\
]\end{array}$ & $\begin{array}{c}\mathrm{P} \\
{[\mathrm{MPa}]}\end{array}$ & $\begin{array}{l}\mathrm{T}[\mathrm{s}] \\
10^{5}\end{array}$ \\
\hline Hub & 3.22 & 252.85 & 65 & 150.715 & 0.764 \\
\hline Mid & 3.52 & 276.40 & 60 & 194.919 & 0.815 \\
\hline Tip & & 299.95 & 55 & 242.653 & 0.926 \\
\hline
\end{tabular}

Also, results prove that erosion and efficiency decrease depend on water droplets diameter, their velocity, impact angles, mass flow rates; aerodynamic features as vortices around the blades; blade shape and profile shape change in radial direction.

\section{Conclusions}

A research on erosion mechanisms, parameters and effects in long turbine blades of complex geometry, is accomplished. A study on particles trajectories and reasons for their deviations is performed.

An approach to calculation of water hammer pressure, number of impacts over surfaces under consideration, incubation time to erosion to appear, over affected surfaces, is implemented.
Numerical methodology (with approaches to attain high quality grid and overcome convergence problems [34]), an implemented UDF code for erosion modeling, together with the analytical model to obtain important erosion parameters, were successfully applied to prediction of erosion effects in last stages of condensation turbines. Important erosion characteristics as volume of droplets, number of particles, number of impacts, incubation time, have been analized, in order to have deeper insights on the erosion phenomena, and provide directions to further prevention.

The outcome of this work highlights the opportunities for future developments in the area of approaches to decrease wetness in the last stages of condensation turbines and to prolong the life cycle of blades operated in wet steam conditions.

\section{References}

[1] Atrens A, Meyer H, Faber G, Schneider K. (1983). Corrosion in Power Generating Equipment. Plenum Press.

[2] White L.C. (1992). Modern Power Station Practice. London: British Electricity International, Pergamon Press.

[3] Viswanathan R. (1989). Damage mechanisms and life assessment of high temperature components. Metals Park: ASME International.

[4] Ansari, A.R (1986). Blade erosion problem in steam turbine, Journal of Institution of Engineers (India)Mech.Eng. 67:1-3

[5] Stodola A. (1922) Dampf- und Gasturbinen. Springer Verlag. Berlin.

[6] Traupel W. (1959). Zur Theorie der Nassdampfturbine, Schweiz. Bauzeitung. 77. S 20, S. 324-328.

[7] B u 11 o c k R.O. Vapor turbine for space power. A. R. S. Paper. 1327-60.

[8] I. I. Kirillov, R. M. Yablonik, L. V. Kartsev, et al., Aerodynamics of the Flow-Through Part of Steam and Gas Turbines [in Russian], Mashgiz, Moscow (1958).

[9] by I. I. Kirillov, R. M. Yablonik, Fundamentals of the theory of turbines operating on wet steam, 1968

[10] Ryley, P.J (1961), Phase equilibrium in low-pressure 3team turbines, Internat. J. Mech. Sc, 5, No. 1-2: 28-46.

[11] Stiver (1963). Yavlenya kondensatcii pri techenii s bolshimi skorostyami (Condensation phenomenon during high speed flow), Collection: Osnovy gazovoy dinamiki, edited by G. Emmons, Izd-vo Inostrannoy literatury, pp.490-fj36.

[12] Leyzerovich, A., (1997). Large Power Steam Turbines: Design and Operation, Penn Well Books.

[13] Grant, G., Tabakoff, W. (1985). Erosion Prediction in Turbomachinery Resulting from Environmental Particles, Journal of Aircraft, Vol. 12, (5): 471-478.

[14] Balan, C., Tabakoff, W. (June 1984). Axial Compressor Performance Deterioration, AIAA Paper 84-1208.

[15] Hamed, A., Tabakoff, W., Rivir, R. B., Das, K., Arora, P. (Jun 2004). Turbine Blade Surface Deterioration by Erosion, ASME-IGTI 2004-54328.

[16] Kline, M., Simpson, G. (Jun 2004). The Development of Innovative Methods for Erosion Testing a Russian 


\section{International Journal of Science and Research (IJSR) \\ ISSN (Online): 2319-7064}

Index Copernicus Value (2013): 6.14 | Impact Factor (2014): 5.611

Coating on GE T64 Gas Turbine Engine Compressor Blades, ASME Paper GT2004-54336.

[17] Tabakoff, W. (1984). Review - Turbomachinery Performance Deterioration Exposed to Solid Particulates Environment, Transactions of ASME, Journal of Fluids Engineering, 106: 125-134.

[18] G. Fiore, M. Selig (2014). A simulation of Operational Damage for Wind turbine Blades, 32nd AIAA Applied Aerodynamics Conference, AIAA Aviation, 16-20 June 2014, Atlanta, GA

[19] Tsubouchi, K., Yasugahira, N., Yoshida, S. (1990). An Evaluation of Water Droplet Erosion for Advanced Large Steam Turbine, PWR-Vol 10, Advances in Steam Turbine Technology for Power Generation, Book No. G00518, pp. 245-251.

[20] Shun-sen Wang, Liu-xi Cai, Jing-ru Mao, Jun-jie Zhang, Ya-tao Xu (2013). Mechanisms of steam turbine blade particle erosion and crucial parameters for minimizing blade erosion, Journal of Power and Energy.

[21] Stanisa, B. and Ivusic, V. (1995). Erosion Be haviour and Mechanisms for Steam Turbine Rotor Blades, Wear, 186-187: 395 - 400.

[22] Nishimura, M (1999), Estimate erosion damage under any conditions, Japan Society of Corrosion Engineering, 48, 6: 355-361.

[23] Xu Wanli, Wang Jiadao, Qin Li, Chen Haosheng, Chen Darong. Investigation of Erosion Damages Induced by Wet Steam Containing Micro-Particles, Tribol Lett, DOI 10.1007/s11249-010-9599-z.

[24] Wroblewski W., Dykas S., Gepert A. (2009). Steam Condensing Flow Modelling in turbine channels, Int. J Multiphase Flows, 35:498-506.

[25] Hamed A., Widen Tabakoff, Rohan Swar, Dongyun Shin, Nathanial Woggen, Robert Miller (2013). Combined Experimental and numerical simulations of thermal barrier coated turbine blades erosion, NASA/TM-2013-217857

[26] Nikkhani B., Shams M., Ziabasharhagh M. (2009). A numerical investigation of two phase steam flow around a 2D turbinees rotor tip, Int. Comm. Heat and Mass Transfer, 36: 632-639

[27] Hasril Hasini, Mohd. Zamri Yusoff, Norhazwani Abd. Malek, Numerical Modelling of Wet Steam Flow in steam Turbine Channel, Mechanical Engineering, Dr. Murat Gokcek (Ed.), ISBN 978-953-51-0505-3, In Tech, 2009, Available from: http://www.intechopen.com/books/mechanicalengineering/ Numerical- Modelling- of- Wet- SteamFlow- in- steam -Turbine- Channel.

[28] Liu-xi Cai, Shun-sen Wang, Juan Di, Jing-ru Mao, Zhenping Feng, Jun-jie Zhang and Ya-tao Xu (2014). Study of Erosion Characteristics of Solid Particles in the First Reheat Stage Blades of a Supercritical Steam Turbine, Paper No. GT2014-26674, pp. V01BT27A040; 13 pages doi:10.1115/GT2014-26674.

[29]Z. Carija, L. Cranjcevic, V. Banic, M. Cavrac (2012). Numerical analysis of Wells turbine for wave power conversion, Engineering Review Vol. 32, Issue 3: 141146.

[30] Mahmood Ebrahimi, Mohammad Hossein Roozbahani (2011). Comparative Investigation in a Turbine Blade Passage Flows with Several Different Turbulence
Models, Int J Advanced Design and Manufacturing Technology, Vol. 4/ No. 4: 39-45.

[31] www.ansys.com

[32] Awatef A. Hamed, W. Tabakoff, R. B. Rivir, et al. (2005). Turbine Blade Surface Deterioration by Erosion, Journal of Turbomachinery, Vol. 127 / 445.

[33] Q. Zhou et al. (2008). Water drop erosion on turbine blades: numerical framework and applications, Materials Transactions, 49 (7): 1606 - 1615.

[34] Galina Ilieva, Numerical Modeling and Research of 3D Turbine Stage, Engineering Applications of Computational Fluid Dynamics, Springer, Advanced Structured Materials series, 44: 103-126, DOI 10.1007/978-3-319-02836-1_8, Online ISBN978-3-31902836-1

[35] Sandeep Soni, J.D. Pandey (2011). Erosion behavior of steam turbine blades of glass-epoxy, IJAET, E-ISSN 0976-3945, 2: 110-117.

[36] www.hyperphysics.phyastr.gsu.edu/hbase/sound/souspe2 .html, cited on 05.09.2015

[37] www.steel-grades.com/pdf/files/Martensitic-stainlesssteels-GB-T-1Cr13.pdf

[38] Richardson, J. H., Sallee, G. P., Smakula, F. K. (Jun 1979). Causes of High Pressure Compressor Deterioration in Service, AIAA Paper 79-1234.

[39] Galina Ilieva, Numerical modeling and research of a 3D turbine stage, Engineering Applications of Computational Fluid Dynamics, Series: Advanced Structured Materials, Springer, Vol. 44, 2015, VI, pp. 103-126. ISBN (online) 978-3-319-02836-1, DOI: 10.1007/978-3-319-02836-1_8. 